\title{
Hearing Outcome of Patients with Acute Noise-Induced Hearing Loss
}

\author{
Byung-Gil Choi ${ }^{1}$, Sung-Kwang Hong ${ }^{1,2}$, Hyung-Jong Kim ${ }^{1,2}$, and Hyo-Jeong Lee ${ }^{1,2}$ \\ ${ }^{1}$ Department of Otorhinolaryngology-Head and Neck Surgery, Hallym University Sacred Heart Hospital, \\ Hallym University College of Medicine, Anyang; and ${ }^{2}$ Laboratory of Brain \& Cognitive Sciences for Convergence Medicine, \\ Hallym University College of Medicine, Anyang, Korea
}

\section{급성 소음성 난청의 청각예후}

최병길 ${ }^{1} \cdot$ 홍성광 $^{1,2} \cdot$ 김형종 $^{1,2} \cdot$ 이효정 ${ }^{1,2}$

한림대학교 의과대학 한림대학교 성심병원 이비인후-두경부외과학교실, ${ }^{1}$ 한림대학교 의과대학 뇌인지융합의학연구소 ${ }^{2}$

Received April 26, 2018

Revised August 13, 2018

Accepted August 31, 2018

Address for correspondence

Hyo-Jeong Lee, MD

Department of Otorhinolaryngology-

Head and Neck Surgery,

Hallym University

Sacred Heart Hospital,

Hallym University

College of Medicine,

22 Gwanpyeong-ro 170beon-gil,

Dongan-gu, Anyang 14068, Korea

Tel +82-31-380-3849

Fax +82-31-386-3860

E-mail hyobravo@gmail.com
Background and Objectives Although poor hearing outcomes have been associated with acute noise-induced hearing loss (ANIHL), only limited studies exist on this issue. This study evaluated the prognosis of ANIHL in comparison to idiopathic sudden sensorineural hearing loss (ISSNHL) and investigated the types of noise causing these disorders.

Subjects and Method Patients with sudden sensorineural hearing loss due to noise exposure were included in the ANIHL group if the threshold shift was more than $30 \mathrm{~dB}$ in three or more consecutive frequencies within the study period (from January 2010 to December 2016). The ANIHL group included 19 patients. As a matched-control group, treated patients with ISSNHL $(n=95)$ were selected as a way of controlling the known prognostic factors that were evenly distributed between groups. Selected prognostic variables used for matching included age, sex, the degree of initial hearing loss, the number of days before the start of treatment, and treatment method.

Results The overall hearing recovery rate of ANIHL was $11 \%$ and that of the control group was $80 \%(p<0.001)$. Noise exposure in military service $(37 \%)$ and leisure activities $(37 \%)$ was the most prominent cause of ANIHL.

Conclusion The hearing outcome of ANIHL was worse than that of ISSNHL. It is thus necessary to establish national guidelines for environmental noise regulations and to raise awareness of hazardous noise exposure.

Korean J Otorhinolaryngol-Head Neck Surg 2019;62(3):151-6

Key Words Noise-induced hearing loss $\cdot$ Prognosis $\cdot$ Sudden hearing loss.

\section{서 론}

급성 소음성 난청은 단속성의 강한 소음에 노출된 이후 급성으로 발현되는 감각신경성 난청의 형태로 나타난다. 이 는 순간적인 음압에 의해 고막 또는 이소골 등의 중이 구조

This is an Open Access article distributed under the terms of the Creative Commons Attribution Non-Commercial License (https://creativecommons.org/licenses/by-nc/4.0) which permits unrestricted non-commercial use, distribution, and reproduction in any medium, provided the original work is properly cited.
나 내이 구조의 손상에 의해 발생하며, 내이 구조의 손상은 와 우의 외유모 세포에 대한 기계적(mechanical) 손상과 대사성 (metabolic) 손상으로 설명할 수 있다. 기계적 손상은 대표적 으로 와우의 내막, 내·외 유모세포, 지지세포, 나선신경절과 혈관조 등에서의 물리적 손상과 내이 혈류의 변화로 나타난 다. 대사성 손상은 미토콘드리아에서의 활성산소(reactive oxygen species)나 활성질소(reactive nitrogen species)와 같은 유리기(free radical)의 과생성으로 인한 와우 혈류 감소, 내이 
세포의 사멸이나 괴사로 발생한다. ${ }^{1,2)}$

급성 소음성 난청은 총기나 폭발음 등 일회성의 강한 소음 혹은 주변의 여과되지 않은 생활 속 환경음이나 여가활동의 소음으로 발생할 수 있으며, 발생한 난청의 회복 여부에 따라 일시적 역치 변화(temporary threshold shift)와 영구적 역치 변화(permanent threshold shift)로 구분할 수 있다. 일시적 역치 변화의 경우 강한 소음 노출 후 대개 24시간 내에 회복을 보이고, 영구적 역치 변화의 경우 소음 노출 후 발생한 난청이 회복되지 않는 형태를 보인다. 일반적으로 고주파 영역에서 의 감각 신경성 난청 및 이명이 동반되는 경우가 많으며, 전정 기능의 장애가 동반되는 경우는 드물다.

선행연구에 따르면 급성 소음성 난청의 경우 급성 감각신 경성 난청의 대표적 질환인 특발성 돌발성 난청에 비해 청력 회복의 측면에 있어 예후가 좋지 못한 것으로 알려져 있으나 현재까지 국·내외적으로 이에 대한 연구는 제한적이다. ${ }^{3-14)}$

따라서 본 연구에서는 급성 소음성 난청 환자군과 동일한 치료를 시행한 특발성 돌발성 난청 환자군 간의 예후를 비교 및 분석하고 현재 국·내외에서 제정되어 있는 소음에 대한 기준을 비교하여 급성 소음성 난청에 대한 예방대책을 제언 하고자 한다.

\section{대상 및 방법}

2010년 1월부터 2016년 12월까지 본원에서 급성 소음성 난청으로 입원 치료를 받은 환자를 대상으로 후향적으로 의 무기록을 분석하였다. 일회성의 큰 소음 노출 병력이 있으면 서 3 개의 연속된 영역의 주파수에서 건측에 비해 $30 \mathrm{~dB}$ 이상 의 청력 소실을 보이는 보이는 경우를 대상으로 하였으며, 3 개 월 이상 추적관찰이 되지 않았거나 중이염 등 이과적 질환이 있는 경우를 제외한 19명을 환자군으로 선정하였다. 동일한 기간에 본원에서 특발성 돌발성 난청으로 치료받은 환자들 중 성별과 초기 청력에서 급성 소음성 난청 환자군과 $5 \mathrm{~dB}$ 이 내의 차이를 보였던 경우로 환자군의 5 배수인 95 명을 선별하 여 대조군으로 선정하였다. 본 연구는 본원의 임상시험연구심 사위원회(Institutional Review Board)의 검토와 승인을 얻은 후 진행하였다(2018-IO17).

급성 소음성 난청 환자군과 대조군으로 선정된 특발성 돌발 성 난청군 모두에서 입원 치료를 시행하였으며, Methylprednisolone $60 \mathrm{mg}$ 을 1 주간 경구로 사용 후 6일에 걸쳐 $10 \mathrm{mg}$ 씩 줄여 중단하였다. 입원 중 안정가료 및 혈관확장제를 병용 투여하였으며 2 일 간격으로 3 회의 성상신경절차단술을 시행 하였다.

입원 당시 순음청력검사, 청성유발반응검사, 전정기능검사
를 시행하였고 입원시의 청력을 초기 청력으로 하였다. 입원 후 2일마다 순음청력검사를 시행하였으며 발생 후 3 개월째 시행한 청력검사 결과를 바탕으로 예후를 평가하였다. 본 연 구에서는 동반된 기저질환이 없고, 청력 저하 발생 후 1 주 이내 치료를 시작한 환자군을 대상으로 하였다.

청력 회복의 판정 기준은 Siegel's criteria ${ }^{15}$ 와 2012년 미국 이비인후과 학회에서 제시한 돌발성 난청에 대한 임상진료지 침에서 제시한 기준 ${ }^{16)}$ 에 따라 평가하였다. Siegel's criteria에 따라 회복 정도에 관계없이 최종 청력이 $25 \mathrm{~dB}$ 이내인 경우 완 전 회복, $15 \mathrm{~dB}$ 이상의 회복과 동시에 최종 청력이 $25 \sim 45 \mathrm{~dB}$ 이내에 있는 경우 부분 회복, $15 \mathrm{~dB}$ 이상의 회복과 동시에 최 종 청력이 $45 \mathrm{~dB}$ 이상인 경우 경도 회복, $15 \mathrm{~dB}$ 이내의 회복 또는 $75 \mathrm{~dB}$ 이상의 최종 청력을 무반응군으로 나누었고, 미 국 임상진료지침에 따라 건측의 청력과 비교하여 최종 청력 에서 $10 \mathrm{~dB}$ 이내, 어음명료도가 5 10\% 이내의 차이를 동시 에 만족할 때 완전 회복, 주관적으로 들을만한 청력으로의 회복되는 경우 혹은 청력에서의 불편함을 호소한 환자들 중 $10 \mathrm{~dB}$ 이상의 청력 회복 혹은 어음명료도의 $10 \%$ 이상의 회복 을 보이는 경우를 부분 회복, $10 \mathrm{~dB}$ 이내의 청력 회복만을 보 이는 경우 무반응군으로 분류하였으며, 두 가지 기준에서 경도 회복 이상의 환자군을 치료에 반응한 군으로 하였다.

청력에 대한 예후를 비교하기 위해 IBM SPSS version 20 program(IBM Corp., Armonk, NY, USA)을 사용하여 chisquare test, Fisher's exact test를 실시하였고, $p$-value 0.05 미만을 통계적 유의성이 있다고 판정하였다.

\section{결 과}

급성 소음성 난청 환자군 19명 중 남자는 14 명(74\%), 여자는 5명(26\%)으로 평균 나이는 38.9( \pm 14.6$)$ 세였으며 대조군 95명 중 남자는 62명(65\%), 여자는 33명(35\%)으로 평균나이( \pm 표 준편차)는 $38.6( \pm 11.8)$ 세였다. 급성 소음성 난청 환자군에서 성별에 따른 유병률과 연령에 따른 유병률 간의 관계는 각각 $p=0.058, p=0.386$ 이었고, 대조군에서는 각각 $p=0.878, p=$ 0.729 로 통계적 유의성은 보이지 않았고, 대상 모두 전정기능 검사상 이상소견은 보이지 않았다(Table 1).

급성 소음성 난청의 주원인으로는 군 소음 노출이 7예, 콘서 트 4예, 레저사격 3예, 공사 현장에서의 폭발음 3예, 고함 1예, 자기공명영상검사 후 발생한 난청 1예로 나타났다.

초기 청력 저하의 정도는 19 예 모두 $60 \mathrm{~dB}$ 이내에서 보였고, Siegel's Criteria에 의거한 청력의 회복률은 급성 소음성 난 청군에서 완전 회복 2예(11\%), 무반응 17예(89\%)로 총 $11 \%$ 가 치료반응을 보였으며, 특발성 돌발성 난청군에서 완전회복 51 
Table 1. Demographic data

\begin{tabular}{lcc}
\hline & ANIHL $(n=19, \%)$ & ISSNHL $(n=95, \%)$ \\
\hline $\begin{array}{l}\text { Gender }(p=0.058) \\
\text { Male }\end{array}$ & $14(74)$ & $62(65)$ \\
Female & $5(26)$ & $33(35)$ \\
Age $(p=0.368)$ & & \\
$<30$ & $7(37)$ & $30(32)$ \\
$30-40$ & $4(21)$ & $25(26)$ \\
$40-50$ & $1(5)$ & $7(7)$ \\
$>50$ & $7(37)$ & $33(35)$ \\
\hline Total & 19 & 95
\end{tabular}

ANIHL: acute noise induced hearing loss, ISSNHL: idiopathic sudden sensorineural hearing loss

Table 2. Hearing outcomes of two groups according to two criteria

\begin{tabular}{lcc}
\hline & ANIHL $(n=19, \%)$ & ISSNHL $(n=95, \%)$ \\
\hline Siegel's Criteria* & & \\
Complete recovery & $2(11)$ & $51(54)$ \\
Partial recovery & - & $10(10)$ \\
Slight recovery & - & $13(14)$ \\
No recovery & $17(89)$ & $21(22)$ \\
AAO-HNS CPG (2012)* & & \\
Complete recovery & $2(11)$ & $51(54)$ \\
Partial recovery & $2(11)$ & $28(29)$ \\
No recovery & $15(78)$ & $16(17)$ \\
\hline
\end{tabular}

*significance at $p<0.05$. ANIHL: acute noise induced hearing loss, ISSNHL: idiopathic sudden sensorineural hearing loss, AAOHNS CPG: Clinical Practice Guidelines of American Academy of Otolaryngology-Head and Neck Surgery

예(54\%), 부분 회복 10예(10\%), 경도 회복 13예(14\%), 무반응 21예(22\%)로 치료반응은 총 78\%에서 보였다. 2012년 미국 임 상진료지침의 기준에 따른 청력의 회복률은 급성 소음성 난 청군에서 완전 회복 2예(11\%), 부분 회복 2예(11\%), 무반응 15예(78\%)로 치료반응은 총 $22 \%$ 로 관찰되었고, 대조군에서 완전 회복 51예(54\%), 부분 회복 28예(29\%), 무호전 16예(17\%) 로 치료반응은 총 83\%에서 보였다. Siegel's Criteria 및 돌발 성 난청에 대한 임상진료지침상 특발성 돌발성 난청군과 급 성 소음성 난청군의 청력 회복률 간의 차이는 모두 $p<0.001$ 로 통계적으로 유의한 차이를 보였다(Table 2). $250 \mathrm{~Hz} 8$ $\mathrm{kHz}$ 에 이르기까지 주파수 별 회복률을 평가하였고, 급성 소 음성 난청 환자군에서 $4 \mathrm{kHz}$ 영역에서 평균 청력의 악화를 보였고, 그 외 영역 및 대조군의 전 영역에서 평균 청력의 호전 을 보였으나 모두 통계적으로 유의하진 않았다. 급성 소음성 난청 환자군의 초기 청력은 4 분법상 평균 $43.9 \mathrm{~dB}$ 이었고 3개 월 추적관찰 후 평균 청력은 $40.7 \mathrm{~dB}$ 로 거의 호전이 없었으나 특발성 돌발성 난청군의 초기 평균 청력은 $50.0 \mathrm{~dB}$ 에서 33.3 $\mathrm{dB}$ 로 급성 소음성 난청 환자군의 청력에 비해 치료반응이 좋 았다(Table 3). 급성 소음성 난청(실선)과 특발성 돌발성 난청
Table 3. Outcomes for hearing recovery by frequency of two groups

\begin{tabular}{ccccccc}
\hline & \multicolumn{2}{c}{ ANIHL group (dB HL) } & & \multicolumn{2}{c}{ ISSNHL group (dB HL) } \\
\cline { 2 - 3 } \cline { 5 - 6 } & Initial & After 3 month & & Initial & After 3 month \\
\hline $250 \mathrm{~Hz}$ & 41.1 & 35.0 & & 46.1 & 23.9 \\
$500 \mathrm{~Hz}$ & 42.4 & 39.2 & & 47.1 & 26.4 \\
$1000 \mathrm{~Hz}$ & 44.5 & 39.7 & & 50.0 & 26.8 \\
$2000 \mathrm{~Hz}$ & 46.3 & 42.6 & & 49.6 & 35.3 \\
$3000 \mathrm{~Hz}$ & 42.4 & 41.1 & & 53.2 & 44.6 \\
$4000 \mathrm{~Hz}$ & 51.1 & 52.1 & & 65.0 & 49.6 \\
$8000 \mathrm{~Hz}$ & 65.0 & 62.1 & & 71.1 & 62.5 \\
Average & 43.9 & 40.7 & & 50.0 & 33.3 \\
\hline
\end{tabular}

ANIHL: acute noise induced hearing loss, ISSNHL: idiopathic sudden sensorineural hearing loss

(점선)의 초기(A) 및 3개월 후(B)의 주파수별 청력 역치의 평 균값을 도식화하였다(Fig. 1). 급성 소음성 난청군에서 완전 회복을 보인 2예의 경우 모두 20대의 젊은 여성으로 콘서트 에 다녀온 이후 발생하였다. 초기 청력은 4분법상 각 $31.3 \mathrm{~dB}$, $60.0 \mathrm{~dB}$ 에서 3개월 후 각각 $13.8 \mathrm{~dB}, 20.0 \mathrm{~dB}$ 로 호전되었고, 후자의 사례는 외래 추적관찰 중 2017년 8월 다시 한 번 콘서 트장 소음에 노출 후 $56.3 \mathrm{~dB}$ 의 급성 소음성 난청이 동측에 재발되어 현재 경과관찰 중이다(Fig. 2).

\section{고 찰}

급성 소음성 난청은 단속성의 강한 소음에 노출된 이후 감각 신경성 난청의 형태로 나타나며 청력의 예후는 불량한 것으로 알려져 있다. 급성 소음성 난청에 있어 청력의 예후를 예측하는 요인을 찾기 위한 선행연구들이 진행된 바 있다. Harada 등,10)은 52명의 급성 음향 외상 환자를 대상으로 나 이, 난청 발생 후 치료까지의 기간, 귀마개의 착용 유무, 초기 청력, 고주파 영역의 청력, 치료약물이 예후에 미치는 영향에 대해 연구하였는데, 난청 발생 후 치료까지의 기간, 초기 청 력, 고주파 영역의 청력을 예후인자로 보고하였다. Tschopp 과 Probst ${ }^{4}$ 가 268명의 환자를 대상으로 수행한 연구에서는 초기 청력의 손실 정도가 예후인자로 보고되었고, 국내에서 Lee 등이 27 명을 대상으로 시행한 연구에서는 난청 발생 후 치료까지의 기간이 예후인자로 보고되었다. 선행연구들에서 적용한 치료 방법은 스테로이드, 비타민, 혈관 확장제 등을 주 된 약제로 사용하였고, 치료제의 종류는 청력의 예후와 유의 한 연관을 보이지 않았다. ${ }^{3,49}$

본 연구에서는 선행연구에서 보고된 예후인자들을 고려하 여 성별, 나이, 초기 청력, 난청 발생 후 치료까지의 기간, 동반 된 기저질환을 가능한 예후인자로 선정하였고, 급성 소음성 난청군과 대조군으로 선정한 특발성 돌발성 난청 환자군에 서 이러한 변수들을 동일하게 분포하도록 조정하여 질환 간에 


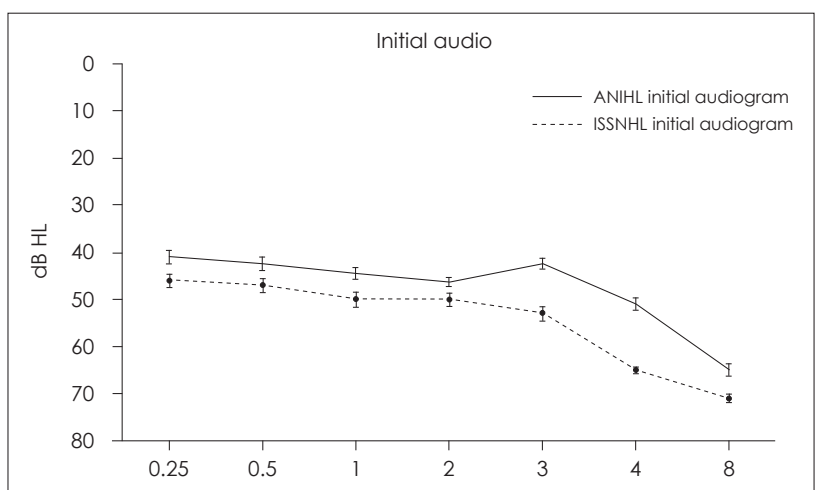

A

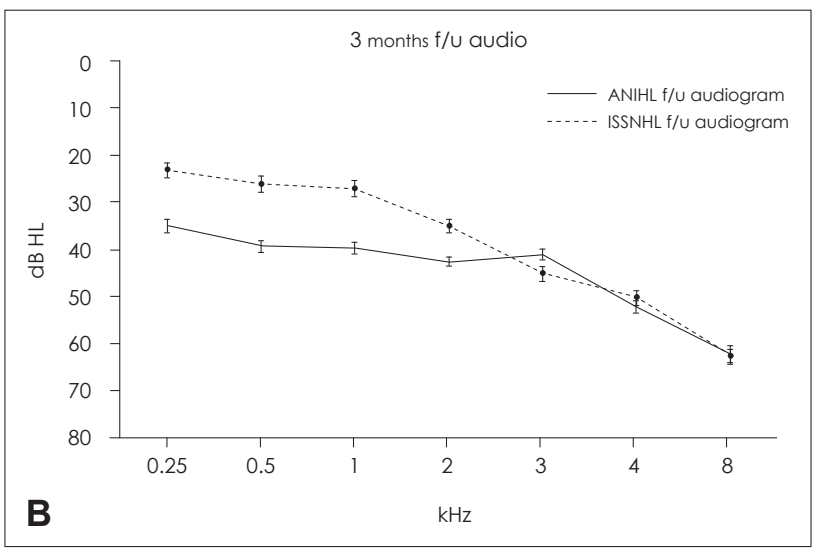

Fig. 1. Audiogram averages of $A N I H L$ group and ISSNHL group at the first visit (A) and 3 months later (B). ANIHL: acute noise-induced hearing loss, ISSNHL: idiopathic sudden sensorineural hearing loss, f/u: follow up.

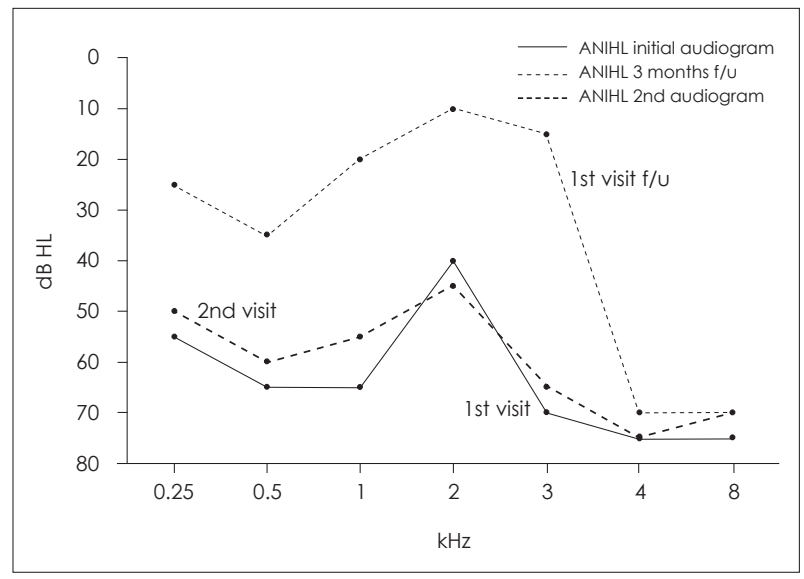

Fig. 2. Audiogram of a case of recurrent ANIHL. Initial audiogram at the 1 st episode of ANIHL, f/u audiogram after 3 months, and audiogram at the 2 nd episode of ANIHL. ANIHL: acute noise-induced hearing loss, f/u: follow up.

청력의 예후만을 비교할 수 있도록 연구를 설계하였고, 후향 적 의무기록 리뷰를 통해 비교분석 하였다.

본 연구에서 청력의 회복률은 선행연구에 비하여 낮게 관 찰되었다. 선행연구에서 급성 소음성 난청의 회복률은 $29 \%$ $40 \%^{3-5,9,10)}$ 를 보였으나 본 연구에서는 $11 \%$ 로 상당히 낮게 보 고되었다. 이는 첫째로 청력 회복률에 대한 평가에 적용된 기준의 차이로부터 기인한 것으로 사료된다. 선행연구에서는 청력 회복률을 위한 평가 기준을 독자적으로 규정하였으며, 본 연구에서 기준으로 적용한 Siegel's criteria ${ }^{15}$ 나 임상진료 지침 ${ }^{16}$ 에 비해 관대한 기준을 적용하였다. 둘째로 연구 대상 의 모집 기준에서 차이를 보였다. 본 연구에서는 소음 노출 후 청력검사 결과 3 개 이상의 주파수에서 $30 \mathrm{~dB}$ 이상의 난청 을 보이는 환자를 모집하였고, 고주파 영역의 청력 소실은 있 으나 난청 없이 이명만을 호소하는 환자는 연구에서 제외하 였다. 하지만 선행연구에서는 소음에 노출된 이후 발생한 난 청뿐 아니라 이명, 전정기능 이상 등 다른 이과학적 증상이
발생한 환자군을 대상으로 한 모집단의 차이로 인해 회복률 에서 차이를 보였을 것으로 생각된다. 또 본 연구에서 대조군 으로 모집한 돌발성 난청 환자군에서도 다른 선행연구에서 보인 50\% 65\% $\%^{3-5,9,10)}$ 의 회복률보다 높은 $78 \%$ 의 회복률을 보였다. 이는 급성 소음성 난청 환자와 예후인자를 동일하게 하기 위해 동반된 기저질환이 없고 난청 발생 후 치료시작 시 점까지의 기간이 1 주 이내인 경우만을 선별한 것에서 기인하 였으리라 사료된다.

특발성 돌발성 난청에 있어 Ahn 등의 의 연구에서는 어지럼 이 없는 경우, Mattox와 Simmons ${ }^{6}$ 는 고주파 영역에서의 청 력 손실 유무, $\operatorname{Kim}$ 등긔 의 연구에서는 초기 청력이 나쁠수록 예후는 좋지 않음을 보고하였다. 또한 Wada 등ㄹㅇㅢ 연구에 서는 급성 소음성 난청과 급성 음향 외상을 구분하여 그 예후 의 차이점을 비교하였다. 청력의 탄성 한계(elastic limit)를 초 과하는 $130 \mathrm{dBA}$ 이상의 큰 소음에 노출된 이후 발생한 난청 을 급성 음향 외상으로 정의하였고, 총기 소음, 폭발음을 일으 키는 원인으로 분류하였다. 급성 음향 외상은 기계적 손상에 의한 난청으로 보았으며, 그 외 특정 노출 시간 동안 탄성 한 계 이하의 소음에서 대사성 손상에 의한 난청을 급성 소음 성 난청으로 정의하고 18 명을 대상으로 하였다. 급성 소음성 난청 환자군의 청력 회복률이 급성 음향 외상군에 비해 좋 은 예후를 보였고, 빠른 시기에 전신적 스테로이드를 투여하 였으나 청력에 있어 대부분 무반응을 보였던 급성 음향 외상 에 대한 새로운 치료의 개발이 시급함도 보고하였다. 이 선행 연구를 참고하자면 급성 소음성 난청과 특발성 돌발성 난청 의 예후를 예측하는 요인에는 차이가 있으며, 향후 국내에서 도 다기관 연구 등을 통해 대규모 환자군을 대상으로 급성 소음성 난청의 예후인자를 분석하는 연구가 필요할 것으로 사료된다.

본 연구에서는 급성 소음성 난청을 유발하는 원인의 특성 
으로 인해 환자군이 남성으로 편향된 모습을 보이고 있었다. Tschopp과 Probst ${ }^{4}$ 의 연구에서도 268 명의 군인을 대상으로 시행하였고, Harada 등 ${ }^{3}$ 의 연구에서도 52 명의 군대 내 소음, Jung 등 ${ }^{17)}$ 도 군대 내 사격 이후 발생한 86 명을 대상으로 연 구하였다. 이와 같이 선행연구에서도 소음 노출의 환경적 특 성으로 남성으로 편향되어 있는 경향을 보인다. Lee 등'의 연구에서는 클럽, 레저사격 등에서의 노출 이후 발생한 난청 환자 27명 중 14 명이 여성이었고, Wada 등 ${ }^{12}$ 의 연구에서도 18 명 중 5 명이 여성에서 발생하였다. 본 연구에서도 전체적으 로는 남성으로 유병률이 치우쳐 있으나 소음의 원인으로 군 소음 노출 이외에도 레저사격, 클럽 및 콘서트 소음 등 레저 활동에서의 소음 노출이 동수를 보이고 있다. 이는 군대와 같 은 제한된 공간뿐만 아니라 여가활동 중 유해한 정도의 큰 소음에 노출될 기회가 늘어나고 있는 사회적 현실을 보여준 다. 따라서 앞으로 소음성 난청의 유병률 상승 및 여성 환자 의 증가의 가능성을 예측해 볼 수 있으며, 추후 다기관 연구 를 통한 전국적 실태조사가 필요할 것으로 사료된다.

본 연구의 피험자 중 급성 소음성 난청 1 예는 동반된 질환 이 없는 20대 여성으로 콘서트장에서의 소음 노출 이후 발생 한 난청에 대하여 치료 후 완전 회복이 되었으나 1 년 후 같은 기전으로 소음에 노출된 후 급성 소음성 난청이 재발하였다. 급성 소음성 난청 이환 환자에 있어서 청력 회복 후 난청의 재발률에 대한 연구는 현재까지 확인되지 않으나, 소음 노출 에 민감한 개인의 다양한 감수성이 관여할 것으로 추정되며, 소음 노출에 대한 강력한 예방 교육이 필수적임을 보여주는 사례이다.

현재까지 급성 소음성 난청에 대한 약물치료는 표준화되어 있지 않으며, 적용하고 있는 약물치료에 대한 반응이 우수하 지 않으므로 예방이 최선의 해결책이다. 미국의 국립 직업안전 건강연구소(The National Institute for Occupational Safety and Health)에서는 소음이 있는 환경에서의 노출 시간제한, 청력 보호장구 착용 및 교육의 중요성을 강조하고 있다. 소음 의 정량을 노출된 시간의 평균적 소음 강도로 나타내고 있으 며 시간 가중 평균 노출(Time-Weighted Average, TWA)이라 는 지표로 사용한다. 미국 직업안전위생관리국(Occupational Safety and Health Administration)의 소음노출허용기준은 $90 \mathrm{dBA} 8 \mathrm{hr}$ TWA로 표시되는데 이는 8시간 동안 평균 90 $\mathrm{dBA}$ 의 소음 노출을 의미한다. 여기에서 $5 \mathrm{~dB}$ 의 교환율(exchanging rate)을 적용하여 시간당 허용되는 소음량을 규정 해 놓았고, 우리나라도 동일한 규준을 사용하고 있다.

위와 같이 제한된 작업공간 내의 예상되는 소음에 대한 규 준은 제정되어 있으나 생활 속 환경음, 여가활동 소음은 노출 되는 시간, 장소 등에 대한 높은 가변성 및 단속성으로 인해
소음에 대한 법적 규준 마련은 현실적으로 어려운 실정이다. 그러한 어려움에도 불구하고 개인의 사적 환경에서 노출되 는 소음의 건강영향에 대한 문제의식의 일환으로 국·내외의 여러 기구에서 현대 사회에서 흔히 접할 수 있는 휴대용 음향 기기에 대한 소음 노출 기준이 발표하였고, 유럽에서는 100 $\mathrm{dB}(\mathrm{A})$ 미만, 미국 직업안전위생관리국에서는 $100 \mathrm{dBA} 2 \mathrm{hr}$ TWA, 세계보건기구는 최대 음량의 $60 \%$ 기준으로 $1 \mathrm{hr}$ TWA, 대한민국의 환경부에서는 유럽과 같은 기준인 100 $\mathrm{dB}(\mathrm{A})$ 미만을 제시하고 있다. ${ }^{18-20)}$ 앞으로 이뿐만 아니라 생 활 속 환경음, 여가 소음의 노출에 대해 면밀히 실태 조사를 실시하여 소음 노출에 대한 규준의 제정 및 소음 노출의 건 강영향을 인지시키는 예방 교육이 시급하다.

\section{Acknowledgments}

This study was supported by the National Research Foundation of Korea (NRF) grant funded by the Korean Government (2016R1A2B4016220).

\section{REFERENCES}

1) Robertson D, Johnstone BM, McGill TJ. Effects of loud tones on the inner ear: a combined electrophysiological and ultrastructual study. Hear Res 1980;2(1):39-43.

2) Shin SO. Updates in noise induced hearing loss. Korean J Otorhinolaryngol-Head Neck Surg 2014;57(9):584-8.

3) Harada H, Shiraishi K, Kato T. Prognosis of acute acoustic trauma: a retrospective study using multiple logistic regression analysis. Auris Nasus Larynx 2001;28(2):117-20.

4) Tschopp K, Probst R. Acute acoustic trauma. A retrospective study of influencing factors and different therapies in 268 patients. Acta Otolaryngol 1989;108(5-6):378-84.

5) Ahn JH, Yoon TH, Chung JW. Analysis of prognosis in patients with sudden sensorineural hearing loss and dizziness. Korean J Otorhinolaryngol-Head Neck Surg 2001;44(10):1032-7.

6) Mattox DE, Simmons FB. Natural history of sudden sensorineural hearing loss. Ann Otol Rhinol Laryngol 1977;86(4 Pt 1):463-80.

7) Kim SM, Park GJ, Lee WY, Kim CA. Clinical analysis of sudden sensorineural hearing loss. Korean J Otorhinolaryngol-Head Neck Surg 1994;37(2):231-9.

8) Yim KC, Park KY, Lee KI, Kim JY, Chun KD. Clinical analysis of sudden hearing loss. Korean J Otorhinolaryngol-Head Neck Surg 1995;38(6):834-41.

9) Lee JK, Yoon YJ, Kim JS, So SS, Kwon SH. Prognostic factors of acute acoustic trauma. Korean J Otorhinolaryngol-Head Neck Surg 2006;49(5):494-8.

10) Harada H, Ichikawa D, Imamura A. Course of hearing recovery according to frequency in patients with acute acoustic sensorineural hearing loss. Int Tinnitus J 2008;14(1):83-7.

11) Lim HW, Lee JW, Chung JW. Vulnerability to acoustic trauma in the normal hearing ear with contralateral hearing loss. Ann Otol Rhinol Laryngol 2014;123(4):286-92.

12) Wada $T$, Sano H, Nishio SY, Kitoh R, Ikezono T, Iwasaki $S$, et al. Differences between acoustic trauma and other types of acute noiseinduced hearing loss in terms of treatment and hearing prognosis. Acta Otolaryngol 2017;137(sup565):S48-S52.

13) Moon IS. Noise induced hearing loss caused by gunshot in military service. Korean J Otorhinolaryngol-Head Neck Surg 2006;49(9): 887-91. 
14) Le TN, Straatman LV, Lea J, Westerberg B. Current insights in noiseinduced hearing loss: a literature review of the underlying mechanism, pathophysiology, asymmetry,and management options. J Otolaryngol Head Neck Surg 2017;46(1):41.

15) Siegel LG. The treatment of idiopathic sudden sensorineural hearing loss. OtolaryngolClin North Am 1975;8(2):467-73.

16) Stachler RJ, Chandrasekhar SS, Archer SM, Rosenfeld RM, Schwartz SR, Barrs DM, et al. Clinical practice guideline: sudden hearing loss. Otolaryngol Head Neck Surg 2012;146(3 Suppl):S1-S35.

17) Jung HW, Lee HI, Kim JY, Joo JB, Cho JE. A study on the effectiveness of treatment of acoustic trauma caused by gunshot noise. Korean J Otorhinolaryngol-Head Neck Surg 2010;53(10):609-14.
18) Occupational Safety and Health Administration. Occupational noise exposure: hearing conservation amendment. Fed Reg 1983;48(46): 9738-85.

19) The European Parliament and of the Council. Commission decision on safety requirements to be met by european standards for personal music players pursuant to directive of the european parliament and of the council. Official Journal of the European Union. 2009;L161: 38-9.

20) Meyer-Bisch C. Epidemiological evaluation of hearing damage related to strongly amplified music (personal cassette players, discotheques, rock concerts)--high-definition audiometric survey on 1364 subjects. Audiology 1996;35(3):121-42. 